УДК 66.074.37

ОЧИСТКА ПОПУТНОГО НЕФТЯНОГО ГАЗА ОТ СЕРОВОДОРОДА

РАСТВОРОМ ЩЕЛОЧИ

\title{
ASSOCIATED PETROLEUM GAS DESULFURIZATION \\ WITH AN ALKALINE SOLUTION
}

Г.А. Нуриева, 3.Р. Гафиуллина

Уфимский государственный нефтяной технический университет, г. Уфа, Российская Федерация

Guzel A. Nurieva, Zulfiya R. Gafiullina

Ufa State Petroleum Technological University, Ufa, Russian Federation

e-mail: shagaza@mail.ru

Аннотация. Ухудшение качества нефти разрабатываемых месторождений и ввод в эксплуатацию месторождений сернистых нефтей приводит к увеличению доли сероводородсодержащего попутного нефтяного газа. Современные технологии утилизации попутного газа предоставляют возможность полностью использовать попутный нефтяной газ на месторождениях, получать дополнительную электроэнергию, углеводородные газомоторные топлива. Одной из наиболее серьезных проблем при утилизации попутного нефтяного газа является его очистка от сероводорода, газоконденсата, влаги и механических примесей. В статье рассмотрена поглотительная способность дистиллированной воды, а также раствора гидроксида натрия разных концентраций. Исследованиями показано, что при использовании в качестве поглотителя дистиллированной воды содержание сероводорода в газе снижается незначительно. При использовании в качестве поглотителя 1,2-10,0 \% раствора щелочи содержание сероводорода в газе снижается в 9,4-5,2 раза. 
Установлено, что оптимальной является концентрация щелочного раствора 1,2-2,5 \%, при этих концентрациях происходит максимальное снижение содержания сероводорода (в 7,8-9,4 раза).

Abstract. The deterioration of the oil fields quality under development and replenishment of reserves due to the fields of sulphurous oils leads to an increase in the share of hydrogen sulfide-containing associated oil gas. Modern technologies for the disposal of associated gas provide an opportunity to fully use associated oil gas in the fields, to receive additional electricity, heat and hydrocarbon gas-engine fuels. One of the most serious problems in the disposal of associated oil gas is its cleaning of hydrogen sulfide, gas condensate, moisture and mechanical impurities. The article examines the absorption capacity of distilled water, as well as the solution of sodium hydroxide of different concentrations. Studies have shown that when used as a distilled water absorber, the hydrogen sulfide content in the gas decreases slightly. When used as a sink $1.2-10.0 \%$ of the solution of lye and reduce the hydrogen sulfide content in the gas is 9.4-5.2 times, at these concentrations there is a maximum reduction in hydrogen sulfide content (7.8-9.4 times).

Ключевые слова: сероводород; щелочь; нефтедобыча; попутный нефтяной газ; компонент; состав; углеводород

Key words: hydrogen sulfide; lye; oil production; associated petroleum gas; component; composition; hydrocarbons

Попутный нефтяной газ (ПНГ) представляет собой смесь различных газообразных углеводородов, растворенных в нефти, выделяющихся в процессе добычи и подготовки нефти. Он является побочным продуктом нефтедобычи, получаемым в процессе сепарации нефти [1-3]. Компонентный состав попутного нефтяного газа представляет собой смесь различных газообразных углеводородов, начиная от метана и заканчивая 
его гомологами вплоть до $\mathrm{C}_{10+}$, а также неуглеводородных газов $\left(\mathrm{H}_{2} \mathrm{~S}, \mathrm{~N}_{2}\right.$, $\mathrm{He}, \mathrm{CO}_{2}$, меркаптанов) и других веществ $[4,5]$.

В последнее время становится актуальной задача утилизации попутного нефтяного газа, получаемого при добыче нефти. Данная тенденция объясняется рядом причин: ростом добычи нефти, ужесточением экологических норм.

Существует несколько способов утилизации ПНГ: сжигание, закачивание газа в пласт и его фракционная переработка, переработка на газоперерабатывающих заводах [6-10]. Попутный нефтяной газ считается одним их ценных видов сырья для нефтехимической промышленности. Сырье используется для получения различных полимеров, каучука, моторного топлива.

Долгое время в связи с неподготовленностью инфраструктуры для сбора, подготовки, транспортировки и переработки ПНГ сжигание считалось основным способом его утилизации, что пагубно влияло на окружающую среду и приводило к глобальным проблемам.

Согласно постановлению Правительства РФ с 1 января 2012 г. все нефтяные компании должны утилизировать не менее 95 \% извлекаемого попутного нефтяного газа, поэтому в настоящее время наблюдается устойчивый рост интереса к переработке природного и попутного нефтяного газа.

Современные технологии утилизации попутного газа предоставляют возможность полностью использовать попутный нефтяной газ на месторождениях, получать дополнительную электроэнергию, тепло и углеводородные газомоторные топлива.

Одной из наиболее серьезных проблем при утилизации попутного нефтяного газа является его очистка от сероводорода, газоконденсата, влаги и механических примесей. Без предварительной очистки от сероводорода не представляется возможным использовать ПНГ на 
производственные нужды месторождения, и единственным приемлемым в этом случае способом обращения с ПНГ является его сжигание.

Ухудшение качества нефти разрабатываемых месторождений и ввод в эксплуатацию месторождений сернистой нефти приводит к увеличению доли сероводородсодержащего попутного нефтяного газа. Попутный нефтяной газ, выделяемый из сернистой нефти месторождений УралоПоволжья и ряда других регионов России, характеризуется относительно невысокими объёмами его производства при сепарации нефти и высоким содержанием сероводорода. При любом варианте использования сернистого ПНГ (как топлива на собственные нужды и сырья для переработки) необходимо предварительное удаление примесей, в частности сероводорода.

Целью данной работы является исследование поглотительной способности щелочи с целью очистки ПНГ в зависимости от ее концентрации.

В промышленной практике для реализации щелочной очистки используют 10 \%-ый раствор едкого натра. Возникает вопрос, что будет, если изменить концентрацию поглотителя?

Исходный 10 \%-ый раствор разбавлялся дистиллированной водой в определенном соотношении и определялся остаточный сероводород в газе.

\section{Методики исследования}

В ходе исследования был использован газовый хроматограф. Пробы были исследованы по ГОСТ 14920-79 «Газ сухой. Метод определения компонентного состава». Настоящий стандарт устанавливает метод определения компонентного состава сухого газа, содержащего углеводороды $\mathrm{C}_{1}-\mathrm{C}_{5}$, a также неуглеводородные компоненты (водород, азот, окись и двуокись углерода и сероводород), массовая доля которых $0,1 \%$ и выше. 
Сущность метода заключается в газожидкостной и газоадсорбционной хроматографии газа с использованием детектора по теплопроводности. Углеводороды $\mathrm{C}_{1}-\mathrm{C}_{5}$, двуокись углерода и сероводород разделяют методом газожидкостной хроматографии. Неуглеводородные компоненты (водород, кислород, азот, окись углерода) и метан разделяют методом газоадсорбционной хроматографии [11].

Универсальным является катарометр - детектор по теплопроводности, принцип работы которого основан на изменении температуры нагретых нитей (чувствительных элементов) в зависимости от теплопроводности окружающего газа, которая определяется его составом. Детектор измеряет различие в теплопроводности чистого газа-носителя и смеси газа-носителя с определяемым веществом [12].

Количественный состав анализируемого газа рассчитан методом внутренней нормализации. Определены приведенные площади пиков $\left(\mathrm{S}_{\mathrm{i}}\right)$ компонентов:

$$
S_{i}=a_{i} \cdot h_{i} \cdot k_{i} \cdot M,
$$

где $a_{i}$ - ширина пика компонента на середине его высоты, мм;

$\mathrm{h}_{\mathrm{i}}$ - высота пика компонента, мм;

$\mathrm{k}_{\mathrm{i}}$ - массовый коэффициент чувствительности;

М - масштаб регистратора хроматограммы.

Массовую долю каждого компонента в процентах:

$$
X_{i}=\frac{S_{i} \cdot 100}{\sum S_{i}} .
$$

Согласно ГОСТ 22985-90 при определении в сжиженных газах сероводорода и меркаптановой серы в качестве поглотителя используется 10 \%-ый раствор гидроокиси натрия (калия) или раствор углекислого натрия и гидроокиси натрия.

Данный раствор подвергается потенциометрическому титрованию. Схема установки представлена на рисунке 1 [13]. 


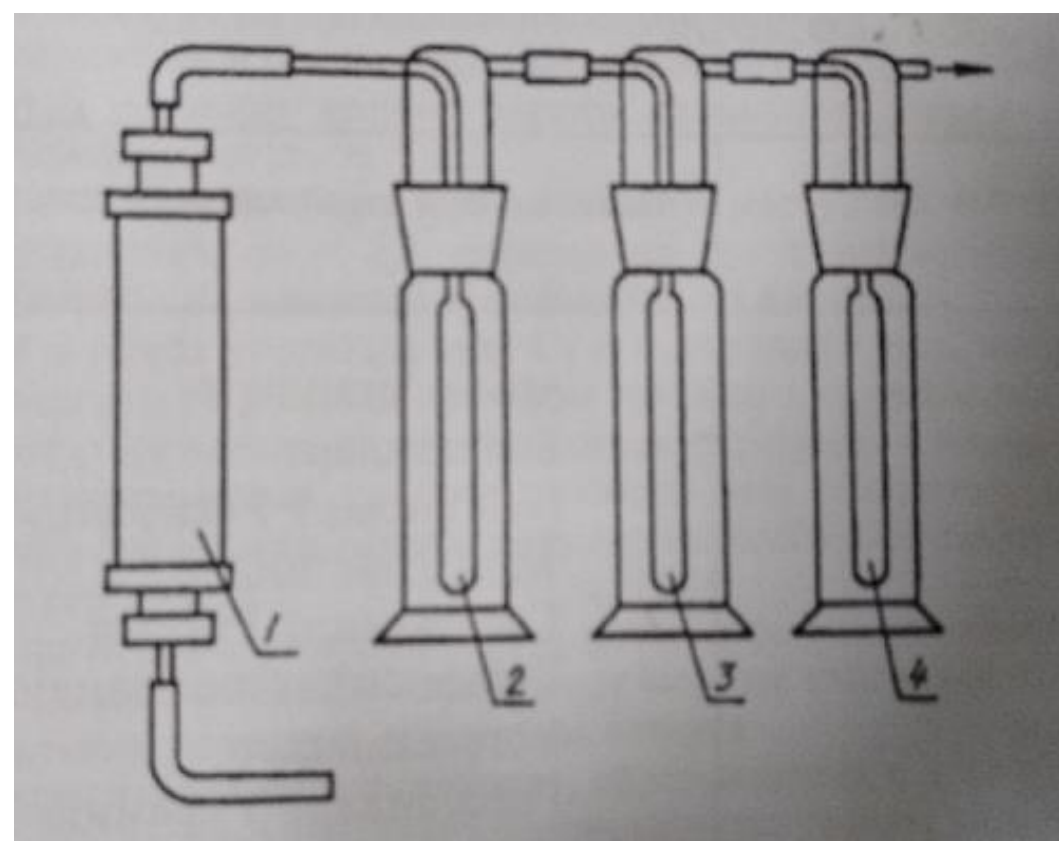

1 - пробоотборник;

2 - предохранительная склянка;

3, 4 - поглотительные склянки

Рисунок 1. Схема установки для поглощения сероводорода и меркаптанов

\section{Экспериментальные исследования}

В первую очередь, определялся компонентный состав исходной пробы согласно ГОСТ 14920-79.

Далее собиралась установка согласно ГОСТ 22985-90 с некоторыми отклонениями. Отличие состояло в том, что, во-первых, исследовался не сжиженный газ, а сухой; во-вторых, поглотительная склянка была в количестве одной штуки вместо двух; в-третьих, в конце схемы присоединялся не газовый счетчик, а пустая камера для того, чтобы собрать газ для последующей разгонки на хроматографе (рисунок 2). 


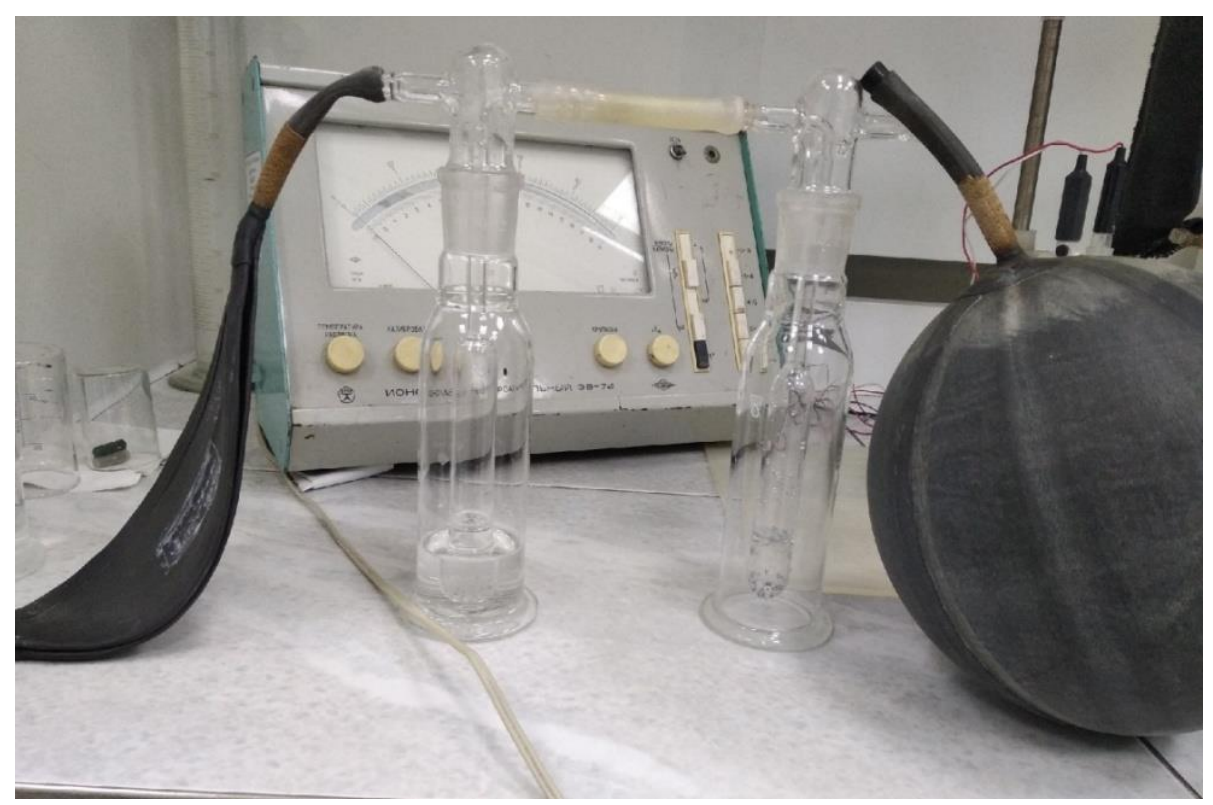

Рисунок 2. Установка для поглощения сероводорода и последующей сборки газа для хроматографии

Использовался 10 \%-ый раствор едкого натра, дистиллированная вода для его разбавления.

На рисунке 3 приведен пример хроматограммы: чем выше концентрация компонента, тем будет больше размеры соответствующей пики.

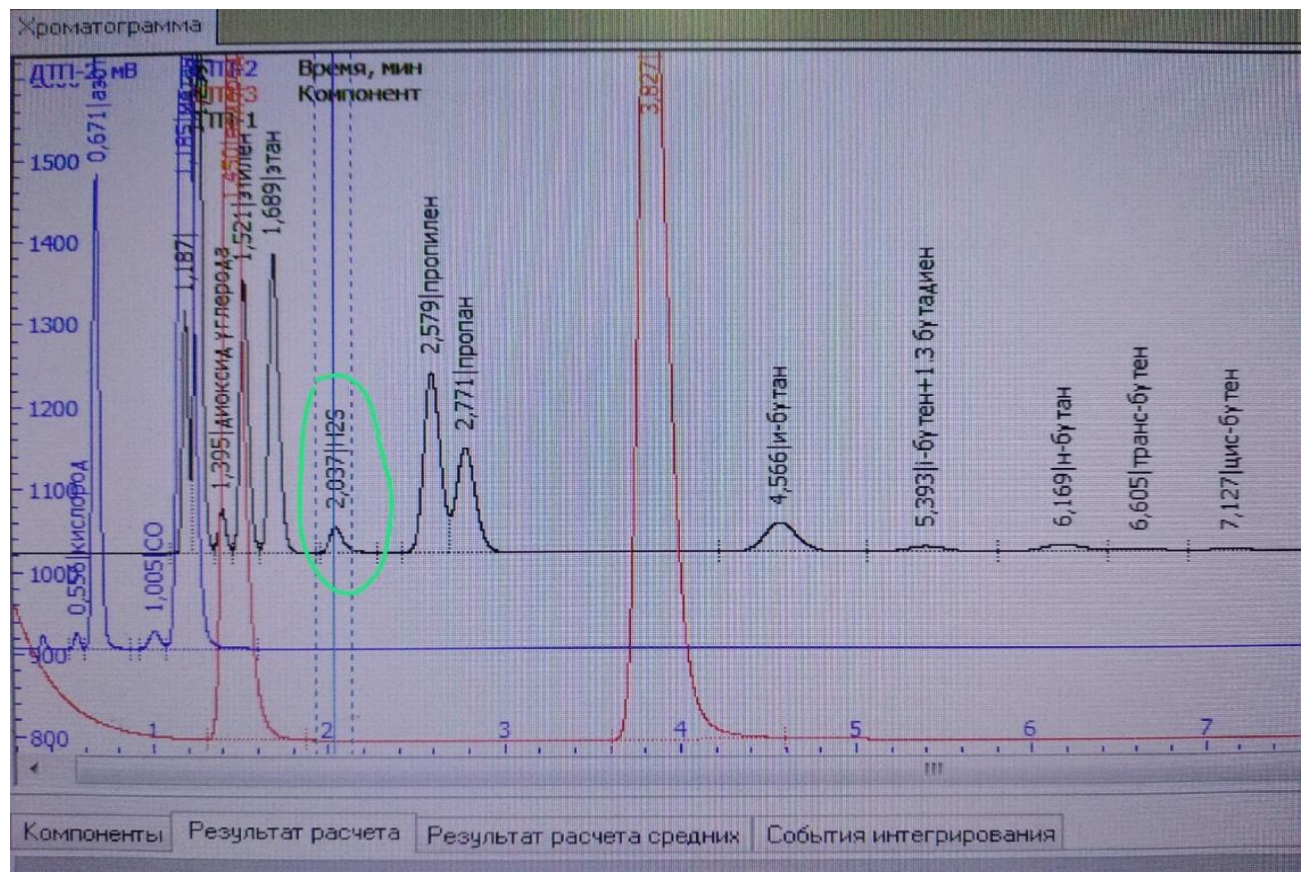

Рисунок 3. Пример хроматограммы 
После продувки газа раствор щелочи окрашивается в желтоватый цвет, что доказывает его поглотительные свойства (рисунок 4).

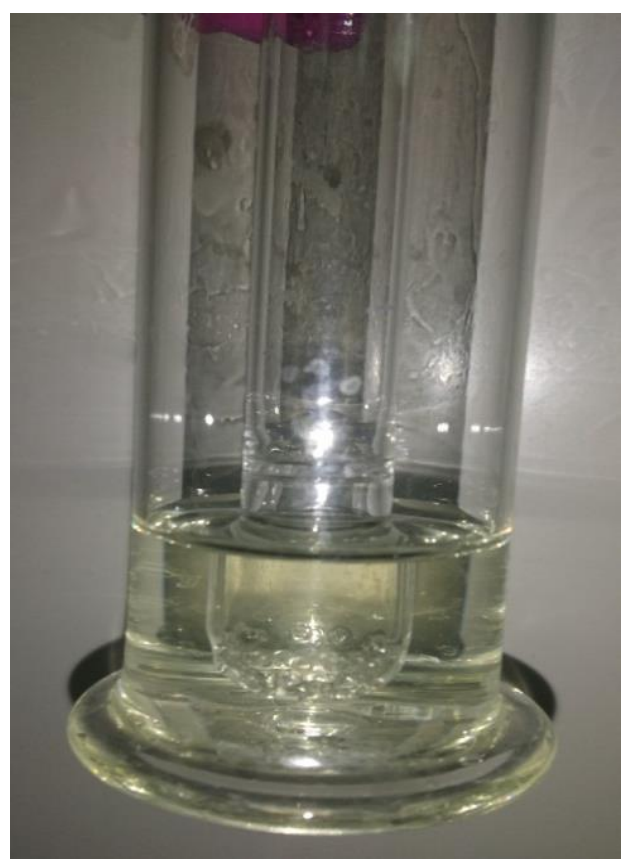

Рисунок 4. Раствор щелочи после пропускания через него исходной пробы

Исходная проба была также пропущена через дистиллированную воду.

\section{Результаты исследований}

Результаты исследований и данные по обработке протоколов анализа хроматораммы представлены в таблицах 1-7.

Таблица 1. Результаты хроматограммы исходного газа

\begin{tabular}{|l|c|c|c|}
\hline \multicolumn{1}{|c|}{ № опыта } & 1 & 2 & 3 \\
\hline Содержание сероводорода, \% об. & 2,82 & 2,62 & 2,70 \\
\hline Содержание сероводорода, \% масс. & 5,02 & 4,47 & 4,50 \\
\hline
\end{tabular}

Таблица 2. Результаты после пропускания газа через воду

\begin{tabular}{|l|c|c|c|}
\hline \multicolumn{1}{|c|}{ № опыта } & 1 & 2 & 3 \\
\hline Содержание сероводорода, \% об. & 1,77 & 1,34 & 1,44 \\
\hline Содержание сероводорода, \% масс. & 3,05 & 2,56 & 2,49 \\
\hline
\end{tabular}


Таблица 3. Результаты после пропускания газа через 1,2 \%-ый раствор щелочи

\begin{tabular}{|l|c|c|c|}
\hline \multicolumn{1}{|c|}{ № опыта } & 1 & 2 & 3 \\
\hline Содержание сероводорода, \% об. & 0,13 & 0,64 & 0,09 \\
\hline Содержание сероводорода, \% масс. & 0,25 & 0,87 & 0,20 \\
\hline
\end{tabular}

Таблица 4. Результаты после пропускания газа через 2,5 \%-ый раствор щелочи

\begin{tabular}{|l|c|c|c|}
\hline \multicolumn{1}{|c|}{ № опыта } & 1 & 2 & 3 \\
\hline Содержание сероводорода, \% об. & 0,30 & 0,25 & 0,21 \\
\hline Содержание сероводорода, \% масс. & 0,68 & 0,42 & 0,55 \\
\hline
\end{tabular}

Таблица 5. Результаты после пропускания газа через 5,0 \%-ый раствор щелочи

\begin{tabular}{|l|c|c|c|}
\hline \multicolumn{1}{|c|}{ № опыта } & 1 & 2 & 3 \\
\hline Содержание сероводорода, \% об. & 0,45 & 0,25 & 0,31 \\
\hline Содержание сероводорода, \% масс. & 0,50 & 0,37 & 0,46 \\
\hline
\end{tabular}

Таблица 6. Результаты после пропускания газа через 10,0 \%-ый раствор щелочи

\begin{tabular}{|l|c|c|c|}
\hline \multicolumn{1}{|c|}{ № опыта } & 1 & 2 & 3 \\
\hline Содержание сероводорода, \% об. & 0,11 & 0,25 & 0,27 \\
\hline Содержание сероводорода, \% масс. & 0,19 & 0,43 & 0,48 \\
\hline
\end{tabular}

Таблица 7. Сводная таблица итоговых результатов

\begin{tabular}{|l|c|c|}
\hline Раствор Содержание & \% об. & \% масс. \\
\hline Исходный газ & 2,71 & 7,00 \\
\hline $0 \%$ & 2,28 & 4,05 \\
\hline $1,2 \%$ & 0,43 & 0,66 \\
\hline $2,5 \%$ & 0,38 & 0,55 \\
\hline $5,0 \%$ & 0,34 & 0,44 \\
\hline $10,0 \%$ & 0,21 & 0,37 \\
\hline
\end{tabular}


Результаты экспериментов показывают, что при использовании в качестве поглотителя дистиллированной воды происходит незначительное снижение содержания сероводорода в газе, далее в исследованиях в качестве поглотителя сероводорода был использован раствор щелочи разной концентрации.

На основании анализа полученных результатов построен график зависимости остаточного содержания сероводорода от концентрации поглотительного раствора (рисунок 5).

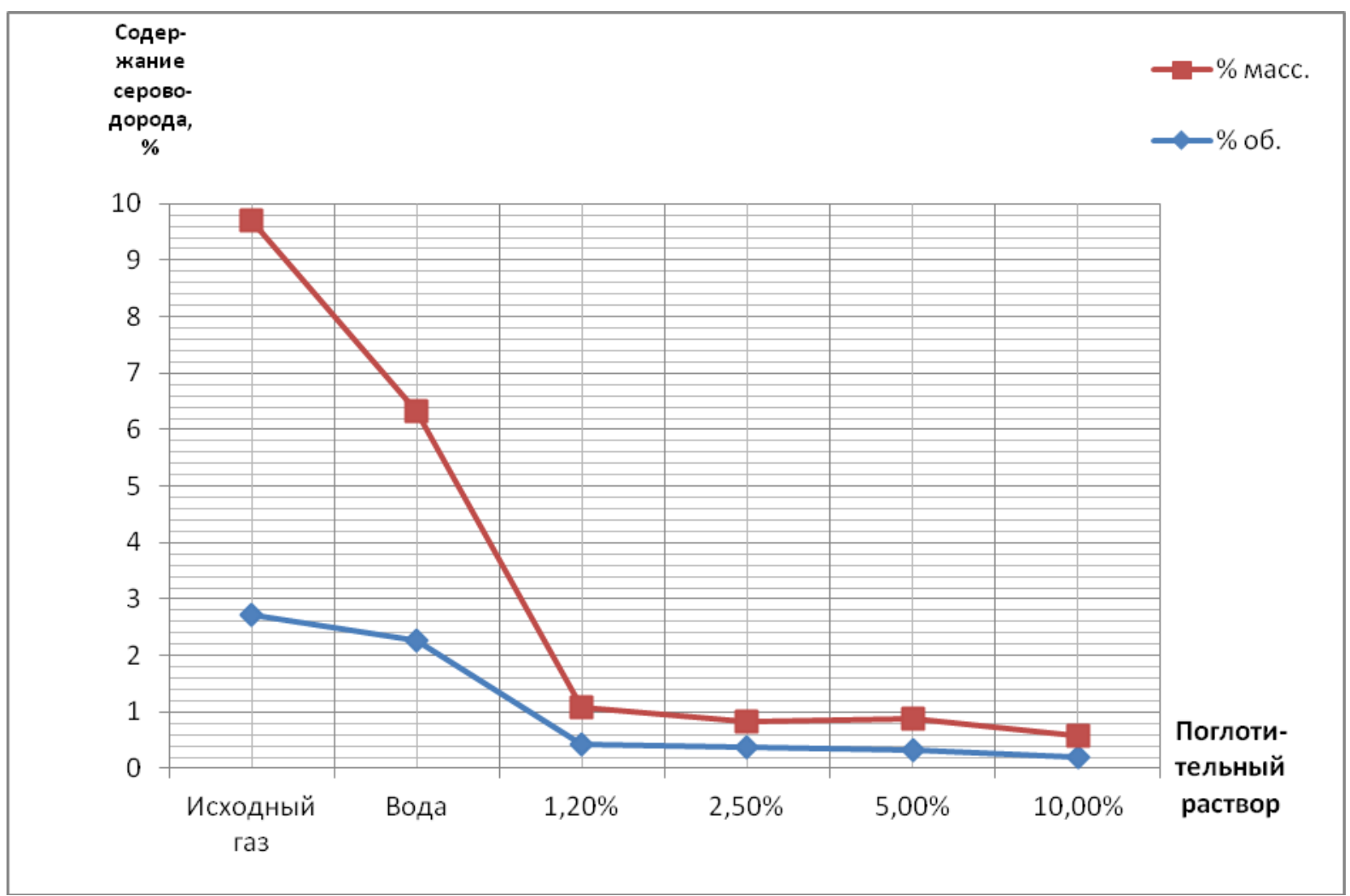

Рисунок 5. График зависимости конечной концентрации сероводорода от поглотительного раствора

\section{Вывод}

Для очистки попутного нефтяного газа от сероводорода в исследованиях в качестве поглотителя использовали дистиллированную воду и раствор щелочи разной концентрации. 
Результаты экспериментов показывают, что при использовании в качестве поглотителя дистиллированной воды содержание сероводорода в газе снижается незначительно. При использовании в качестве поглотителя 1,2\%-го; 2,5\%-го; 5,0\%-го и $10 \%$-го растворов щелочи содержание сероводорода в газе снижается в 9,4; 7,8; 6,2 и 5,2 раза соответственно. Установлено, что оптимальными являются концентрации щелочного раствора 1,2-2,5 \%, при которых происходит максимальное снижение содержания сероводорода (в 7,8-9,4 раза).

\section{Список используемых источников}

1. Игитхаян И.А., Богак Т.В. Эффективность методов переработки попутного нефтяного газа в России // Вестник Томского государственного педагогического университета. 2014. № 8. С. 108-112.

2. Свиридова О.С., Коварская Г.Г., Новак Г.И. Использование ПНГ: организационные, экономические и правовые проблемы и пути их решения // Нефть, газ и бизнес. 2015. № 2. С. 7-12.

3. Элияшевский И.В. Технология добычи нефти и газа. М.: Недра, 1976. $256 \mathrm{c}$.

4. Гельфгат Я.А. Добыча нефти и газа в России: неиспользованные резервы // Энергия: экономика, техника, экология. 2004. № 3. С. 25-31.

5. Кравцов А.В., Смольянинова Н.М., Кузнецова В.А. Исследование компонентного состава попутного газа Самотлорского нефтяного месторождения // Известия Томского ордена Октябрьской революции и ордена трудового Красного знамени Политехнического института им. С.М. Кирова. 1976. № 2. С. 38-39.

6. Полищук Ю.М., Ященко И.Г. Сравнительный анализ качества российской нефти // Нефть и капитал. 2003. № 1. С. 21-24.

7. Реутов Ю.И., Грошев А.Р., Новиков А.А., Никитин Р.Г. Анализ эффективности переработки полученного нефтяного газа // Вестник Югорского государственного университета. 2006. № 2 (3). С. 3-10. 
8. Ахметов Р.Ф., Сидоров Г.М., Рахимов М.Н. Анализ способов переработки попутного нефтяного газа // Наука и техника в газовой промышленности. 2015. № 1 (61). С. 38-44.

9. Ахметов Р.Ф., Сидоров Г.М. Очистка природных и попутных нефтяных газов в трехпоточных вихревых трубах Ранка-Хилша // Теория и практика массообменных процессов химической технологии (Марушкинские чтения): сб. науч. тр. по матер. V Междунар. науч. конф. Уфа: УГНТУ, 2016. С. 181-183.

10. Ахметов Р.Ф., Сидоров Г.М., Ильин Р.Д. Химическая переработка ПНГ // Молодежная наука в развитии регионов: матер. IV Bcepocc. конф. студентов и молодых ученых. Пермь: ПНИПУ, 2014. С. 48.

11. ГОСТ 14920-79. Газ сухой. Метод определения компонентного состава. СПб.: ДЕАН, 1989. 8 с.

12. Пирогов А.В., Шаповалова Е.Н. Хроматографические методы анализа. М.: Академия, 2007. 156 с.

13. ГОСТ 22985-90. Газы углеводородные сжиженные. Метод определения сероводорода и меркаптановой серы. СПб.: ДЕАН, 1991. 14 с.

\section{References}

1. Igitkhayan I.A., Bogak T.V. Effektivnost' metodov pererabotki poputnogo neftyanogo gaza $v$ Rossii [Efficiency of Modern Methods of OilAssociated Gas Refining in Russia]. Vestnik Tomskogo gosudarstvennogo pedagogicheskogo universiteta - Tomsk State Pedagogical University Bulletin, 2014, No. 8, pp. 108-112. [in Russian].

2. Sviridova O.S., Kovarskaya G.G., Novak G.I. Ispol'zovanie PNG: organizatsionnye, ekonomicheskie i pravovye problemy i puti ikh resheniya [Use of Associated Oil Gas: Organizational, Economic and Legal Problems and Ways of their Decision]. Neft', gaz i biznes - Oil, Gas and Business, 2015, No. 2, pp. 7-12. [in Russian]. 
3. Eliyashevskii I.V. Tekhnologiya dobychi nefti $i$ gaza [Oil and Gas Production Technology]. Moscow, Nedra Publ., 1976. 256 p. [in Russian].

4. Gelfgat Ya.A. Dobycha nefti i gaza v Rossii: neispol'zovannye rezervy [Oil and Gas Production in Russia: Unused Reserves]. Energiya: ekonomika, tekhnika, ekologiya - Energy: Economy, Technology, Ecology, 2004, No. 3, pp. 25-31. [in Russian].

5. Kravtsov A.V., Smolyaninova N.M., Kuznetsova V.A. Issledovanie komponentnogo sostava poputnogo gaza Samotlorskogo neftyanogo mestorozhdeniya [Investigation of the Component Composition of Associated Gas of the Samotlor Oil Field]. Izvestiya Tomskogo ordena Oktyabr'skoi revolyutsii i ordena trudovogo Krasnogo znameni Politekhnicheskogo instituta im. S.M. Kirova - News of the Tomsk Order of the October Revolution and the Order of the Red Banner of Labor of the Polytechnic Institute. CM. Kirova, 1976, No. 2, pp. 38-39. [in Russian].

6. Polishchuk Yu.M., Yashchenko I.G. Sravnitel'nyi analiz kachestva rossiiskoi nefti [Comparative Analysis of the Quality of Russian Oil]. Neft' $i$ kapital-Oil and Capital, 2003, No. 1, pp. 21-24. [in Russian].

7. Reutov Yu.I., Groshev A.R., Novikov A.A., Nikitin R.G. Analiz effektivnosti pererabotki poluchennogo neftyanogo gaza [Analysis of the Processing Efficiency of the Obtained Oil Gas]. Vestnik Yugorskogo gosudarstvennogo universiteta - Yugra State University Bulletin, 2006, No. 2 (3), pp. 3-10. [in Russian].

8. Akhmetov R.F., Sidorov G.M., Rakhimov M.N. Analiz sposobov pererabotki poputnogo neftyanogo gaza [Analysis of Associated Petroleum Gas Processing Methods]. Nauka i tekhnika v gazovoi promyshlennosti - Science and Technology in the Gas Industry, 2015, No. 1 (61), pp. 38-44. [in Russian]. 
9. Akhmetov R.F., Sidorov G.M. Ochistka prirodnykh i poputnykh neftyanykh gazov $\mathrm{v}$ trekhpotochnykh vikhrevykh trubakh Ranka-Khilsha [Purification of Natural and Associated Petroleum Gases in Three-Line RankHills Vortex Tubes]. Sbornik nauchnykh trudov po materialam $V$ Mezhdunarodnoi nauchnoi konferentsii «Teoriya i praktika massoobmennykh protsessov khimicheskoi tekhnologii (Marushkinskie chteniya)» [Collection of Scientific Papers on the Materials of the V International Scientific Conference «Theory and Practice of Mass Transfer Processes of Chemical Technology (Marushkin Readings)»]. Ufa, UGNTU Publ., 2016, pp. 181-183. [in Russian].

10. Akhmetov R.F., Sidorov G.M., Ilin R.D. Khimicheskaya pererabotka PNG [APG Chemical Processing]. Materialy IV Vserossiiskoi konferentsii studentov $i$ molodykh uchenykh «Molodezhnaya nauka v razvitii regionov» [Materials of the IV All-Russian Conference of Students and Young Scientists «Youth Science in the Development of Regions»]. Perm, PNIPU Publ., 2014, pp. 48. [in Russian].

11. GOST 14920-79. Gaz sukhoi. Metod opredeleniya komponentnogo sostava [State Standard 14920-79. Dry Gas. Method for Determination of Component Composition]. Saint-Petersburg, DEAN Publ., 1989. 8 p. [in Russian].

12. Pirogov A.V., Shapovalova E.N. Khromatograficheskie metody analiza [Chromatographic Analysis Methods]. Moscow, Akademiya Publ., 2007. 156 p. [in Russian].

13. GOST 22985-90. Gazy uglevodorodnye szhizhennye. Metod opredeleniya serovodoroda i merkaptanovoi sery [State Standard 22985-90. Liquefied Hydrocarbon Gases. Method for Determination of Hydrogen Sulphide and Mercaptan]. Saint-Petersburg, DEAN Publ., 1991. 14 p. [in Russian]. 


\section{Сведения об авторах}

\section{About the authors}

Нуриева Гузель Азатовна, магистрант кафедры «Технология нефти и газа», УГНТУ, г. Уфа, Российская Федерация

Guzel A. Nurieva, Undergraduate Student of Oil and Gas Processing Department, USPTU, Ufa, Russian Federation

e-mail: shagaza@mail.ru

Гафиуллина Зульфия Разифовна, студент кафедры «Технология нефти и газа», УГНТУ, г. Уфа, Российская Федерация

Zulfiya R. Gafiullina, Student of Oil and Gas Processing Department, USPTU, Ufa, Russian Federation

e-mail: tng@rusoil.net 